\title{
Influence of Light Intensity on Growth and Physiological Characteristics of Common Sage (Salvia officinalis L.)
}

\author{
George Zervoudakis ${ }^{*}$, George Salahas, George Kaspiris and Eleni Konstantopoulou \\ Department of Greenhouse Crops and Floriculture; Technological Institute of Mesologgi, 30200 Nea Ktiria; \\ Mesologgi - Greece
}

\begin{abstract}
The aim of this work was to investigate the effects of four different light intensities on the growth characteristics, physiological parameters and leaf photosynthetic pigments of Salvia officinalis L. The plant's dry mass, number of the leaves and physiological parameters indicated a strong positive correlation with the light intensity. On the other hand, the plant's height and leaf photosynthetic pigments were increased at low light treated plants. These results suggest that the aromatic herb Salvia officinalis L. is adaptable to different light environments.
\end{abstract}

Key words: growth, photosynthetic pigments, physiological parameters, Salvia officinalis, solar radiation

\section{INTRODUCTION}

Among the main environmental factors, solar radiation is the most significant one that regulates the photosynthesis, and consequently, the plant survival, growth and adaptation. In any habitat the light intensity varies temporally (seasonally and diurnally) and spatially. Therefore, plants develop acclimation and plasticity to cope with the varying light regimes (Zhang et al. 2003). The majority of plant species have the ability to develop anatomical, morphological, physiological and biochemical alterations in response to different light intensities (Czeczuga 1987; Muraoka et al. 2002; Sousa Paiva et al. 2003; De Carvalho Gonçalves et al. 2005).

According to previous comparative studies, the biomass of roots, stems, leaves and whole plant as well as the photosynthetic rate, the transpiration and the stomatal conductance of water vapor decreased under low light (Zhang et al. 2003; An and Shangguan 2009; Wang et al. 2009; Mielke and Schaffer 2010). On the contrary, plant height increased at low light intensity (Yang et al. 2007; Wang et al. 2009). Besides, plant leaves expanded under high irradiance presented lower photosynthetic pigments contents than leaves expanded under low irradiance (Czeczuga 1987; Adamson et al. 1991; De Carvalho Gonçalves et al. 2005; Yang et al. 2007; Mielke and Schaffer 2010).

Salvia officinalis L. (common sage) is an aromatic perennial evergreen subshrub. It belongs to the Lamiaceae family and is native to the Mediterranean region. Since ancient times, it has been used in folk medicines for the treatment of all kinds of diseases and in a variety of food preparations. Today, it is cultivated in several countries mainly to obtain the dried leaves to be used as raw material in medicine, perfumery, food industry (Santos-Gomes et al. 2002) and as ornamental garden plant (Devecchi 2006). The usefulness of sage is mostly related to the activity of several secondary metabolites, especially

*Author for correspondence: gzervou@teimes.gr 
essential oils and phenolic compounds, which are antioxidant (Pizzale et al. 2002; Santos-Gomes et al. 2002), gastroprotective (Mayer et al. 2009), hepatoprotective (Lima et al. 2005; 2007), antimicrobial, spasmolytic, antiviral etc. (Bozin et al. 2007).

Recently, studies have been focused on the effect of some abiotic stress factors (just as water deficit (Bettaieb et al. 2009; Corell et al. 2009) or hydrogen (Ilkiu-Vidal et al. 2010), salt (Taarit et al. 2009) and phosphorus (Nell et al. 2009) soil concentrations) on Salvia officinalis growth, productivity and secondary metabolites composition.

S. officinalis is an economically interesting plant considering that together with Rosmarinus officinalis L. has the strongest antioxidant activities among the herbs (Santos-Gomes et al. 2002). It has been characterized as one of the "sun species" of the Lamiaceae family (Castrillo et al. 2005). The aim of the present study was to examine the plant growth, physiological parameters and leaf photosynthetic pigments contents in order to evaluate the physiological adaptations of $S$. officinalis plants grown under different solar radiation conditions.

\section{MATERIALS AND METHODS}

\section{Plant material and growth conditions}

Forty S. officinalis L. young seedlings of the same height (about $7 \mathrm{~cm}$ ) were obtained from a nursery. They were transferred to an experimental greenhouse of the Technological Institute of Mesologgi and transplanted to 41 pots filled with perlite. All the plants were grown under a shade cloth (about $25 \%$ of full ambient light) for 15 days for an acclimation period. The plants were irrigated 2-3 times with water and thenceforth with a nutrient solution containing: $6 \mathrm{mM} \mathrm{KNO}_{3}, 4 \mathrm{mM}$ $\mathrm{Ca}\left(\mathrm{NO}_{3}\right)_{2}, 2 \mathrm{mM} \mathrm{MgSO}{ }_{4}, 1 \mathrm{mM} \mathrm{KH_{2 }} \mathrm{PO}_{4}, 4 \mathrm{mM}$ $\mathrm{MgCl}_{2}, 42 \mu \mathrm{M}$ NaFe-EDTA, $46 \mu \mathrm{M} \mathrm{H}_{3} \mathrm{BO}_{3}, 9 \mu \mathrm{M}$ $\mathrm{MnCl}_{2}, 0.76 \mu \mathrm{M} \mathrm{ZnSO}, 0.32 \mu \mathrm{M} \mathrm{CuSO}_{4}$ and 0.12 $\mu \mathrm{M} \mathrm{MoNa}{ }_{2} \mathrm{O}_{4}$. During the experimental period, the nutrient solution $\mathrm{pH}$ ranged between 6.5 and 7.0. All the plants were irrigated with equal volume of nutrient solution at regular periods depending on the weather and soil moisture status, especially in the hottest months.

After the acclimation period, the seedlings were divided at random into four groups which were subjected to four different light intensities obtained with shade cloths. The treatments were: (1) $100 \%$ of full ambient light (FAL) (treated without shade cloth); (2) $75 \%$ of FAL; (3) $50 \%$ of FAL and (4) $25 \%$ of FAL. The Photosynthetic Active Radiation (PAR) incident on leaf surface was about $1400 \mu \mathrm{mol} /\left(\mathrm{m}^{2} \mathrm{~s}\right)$ for full ambient light on a sunny day.

Upon completion of the experiment after three months, the height of all plants was measured. Five plants from each group were harvested and leaves, shoots and roots were separated from each individual, counted and weighed. To obtain the growth measurements, samples were dried to constant weight in an oven at $85^{\circ} \mathrm{C}$.

\section{Leaf gas exchange}

Nondestructive measurements of the photosynthetic and transpiration rate and stomatal conductance obtained with the LCi Portable Photosynthesis System (ADC, BioScientific Ltd., England) at 11:00 a.m. on healthy, completely expanded young leaves ( $3^{\text {rd }}$ node from the top of the shoot). All the measurements were conducted on sunny days in the greenhouse, 60 and 75 days after the installation of the plants to their respective light regimes.

Gas exchange measurements were conducted for three plants per treatment under their respective light regimes.

\section{Chlorophylls and carotenoids}

The leaf samples were of the same physiological age with those used for gas exchange measurements ( $3^{\text {rd }}$ node from the top of the shoot). Leaves were collected from the plants, wrapped in plastic bags and transferred immediately to the lab for photosynthetic pigments contents estimation.

Four leaf discs (diameter $1.2 \mathrm{~cm}$ ) were obtained from each sample (two leaves from each treatment) and weighed. Four similar discs were obtained from the same sample leaves and dried to constant weight in an oven at $85^{\circ} \mathrm{C}$.

The extraction procedure of the photosynthetic pigments was carried out under dim light. The leaf discs were ground in porcelain mortar using $100 \%$ acetone. The resulting suspension was centrifuged at $4^{\circ} \mathrm{C}$ at $2000 \mathrm{~g}$ for $10 \mathrm{~min}$. Chlorophyll and carotenoids contents were determined in acetone supernatants according to the method of Lichtenthaler (1987). The absorbance was determined with a Shimadzu UV-1601 spectrophotometer (Shimadzu Corp., Japan). 


\section{Data analysis}

All data were plotted using Microsoft Office Excel 97-2003. Data are expressed as mean \pm S.E. Statistical analysis was performed with the aid of the Statgraphics Plus 5.1 statistical package. The means of values were compared by Duncan's multiple range test $(\mathrm{p}=0.05)$.

\section{RESULTS AND DISCUSSION}

\section{Plant growth}

Both the plant dry mass (leaf, shoot, root and whole plant) and the number of the leaves responded similarly to light intensity (Fig. 1 and 2). They were the highest at FAL and decreased as much as the plants were shaded. The decrement was $30-50 \%$ for the plants which were grown under $25 \%$ of FAL. The above results indicated that high-light grown S. officinalis plants yielded greater productivity than low-light grown ones just like was shown for several other plants (Adamson et al. 1991; An and Shangguan 2009; Mielke and Schaffer 2010; Pegoraro et al. 2010). However, it has been reported that the intermediate light conditions (about $50 \%$ of FAL) were more adequate for some species to reach higher levels of biomass productivity (De Carvalho Gonçalves et al. 2005).

On the other hand, the height of S.officinalis plants was increased as the light intensity decreased (Fig. 2). In particular, the plants which were grown under $25 \%$ of FAL became about $70 \%$ taller than the plants grown under full sunlight. These findings were in agreement with studies on other plants (Yang et al. 2007; Wang et al. 2009) and resembled to etiolated grown plants which have unusually tall appearance (Taiz and Zeiger 2002).

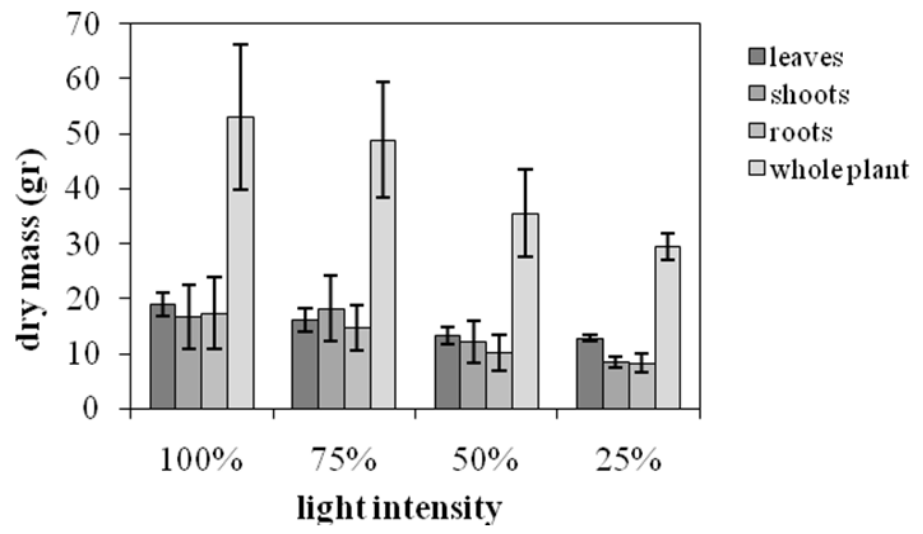

Figure 1 - The effect of light intensity on dry mass productivity. Each value of mean and standard error represents measurements from five plants.

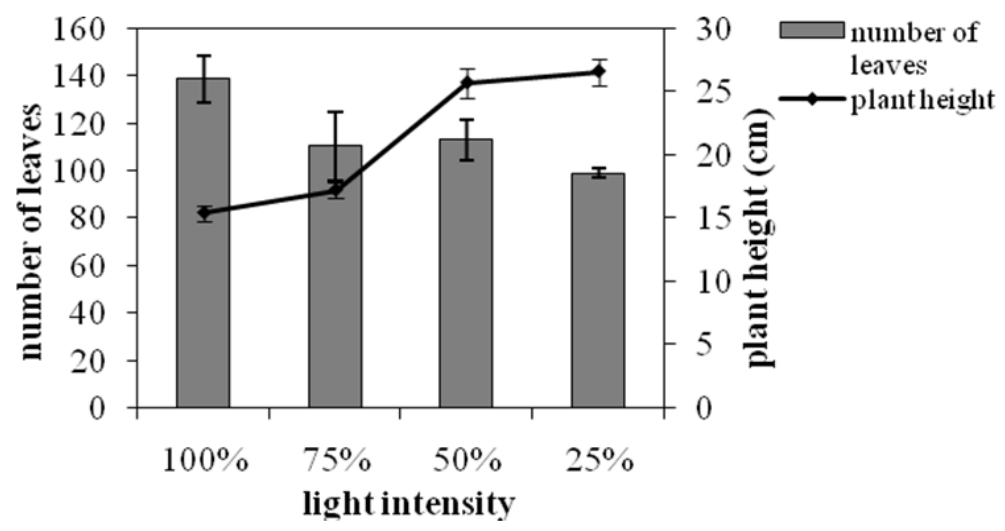

Figure 2 - The effect of light intensity on the total number of the plant leaves and the plant height. Each value of mean and standard error represents measurements from five and ten plants, respectively. 


\section{Leaf gas exchange physiological parameters}

The photosynthetic (Fig. 3) and transpiration rate (Fig. 4) as such the stomatal conductance (Fig. 5) showed a strong positive correlation with the light intensity. The plants grown under $25 \%$ of FAL showed substantial decrements (about 70, 30 and $50 \%$ for the photosynthesis, transpiration and stomatal conductance, respectively) compared with the ones grown under $100 \%$ of FAL 60 days after the installation of the plants to their respective light regimes.

On the other hand, the decrements were smaller for the measurements taken at 75 days after the installation of the plants to their respective light regimes. In particular, the photosynthetic rate decreased $60 \%$ while the stomatal conductance decreased only $20 \%$ and transpiration rate was unaffected, suggesting that the photosynthesis reduction was not induced by the stomatal closure. The high photosynthetic rate under full sunlight was in accordance with studies on other plants (An and Shangguan 2009; Wang et al. 2009; Mielke and Schaffer 2010), and corresponded to the higher soluble sugar content in full light grown Lamiaceae species in comparison with the low light grown ones (Castrillo et al. 2005), and probably demonstrated the high levels of biomass productivity (Fig. 1). However, some other plants may show maximum productivity under full sunlight while their photosynthetic capacity is optimum under moderate shade (Adamson et al. 1991) and others may show both maximum productivity and photosynthetic capacity under moderate shade (De Carvalho Gonçalves et al. 2005).The photosynthetic rate measured at the 75th day compared to the respective one measured at the 60th day showed an about $15 \%$ reduction for the plants grown under 100 and $75 \%$ of FAL, while there was no significant difference for the plants grown under 50 and 25\% of FAL (Fig. 3).

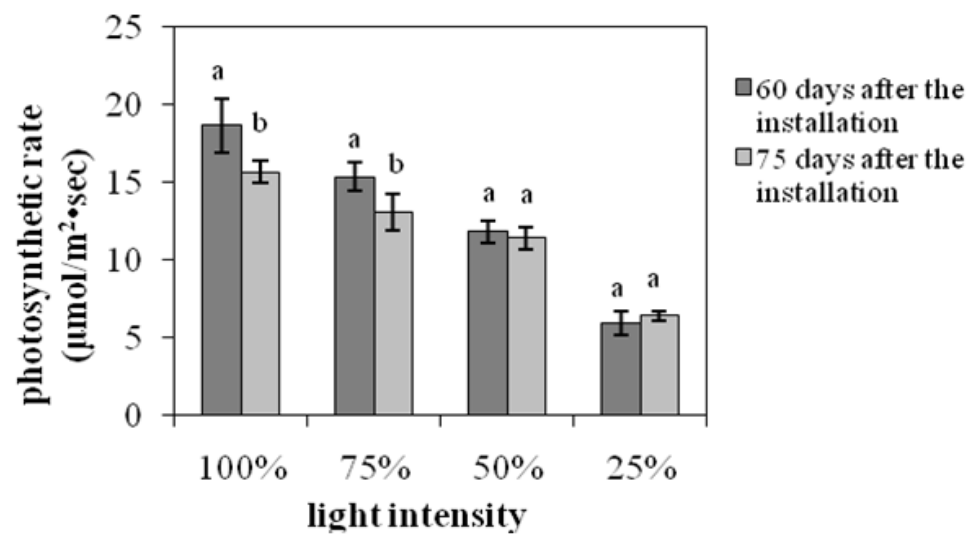

Figure 3 - The effect of light intensity on the photosynthetic rate. Each value of mean and standard error represents measurements from three plants. Significant differences between the means for 60 and 75 days at each light intensity are indicated by different letters $(\mathrm{p}=0.05)$.

The transpiration rate and the stomatal conductance indicated a similar trend (Fig. 4 and 5). In particular, they both showed significant reduction for the plants grown under 100, 75 and $50 \%$ of FAL, while there was no significant difference for the plants grown under $25 \%$ of FAL.
These findings indicated that a longer exposure to higher light intensities could damage the $S$. officinalis photosynthetic apparatus, leading to partial loss of its photosynthetic function as has been suggested for Paeonia suffruticosa too (Zhang et al. 2003). 


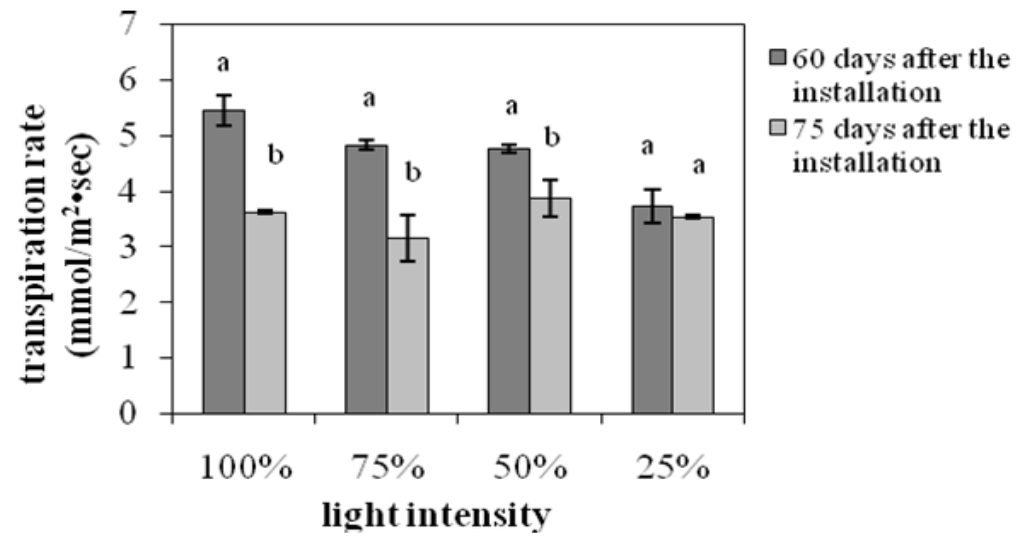

Figure 4 - The effect of light intensity on the transpiration rate. Each value of mean and standard error represents measurements from three plants. Significant differences between the means for 60 and 75 days at each light intensity are indicated by different letters $(\mathrm{p}=0.05)$.

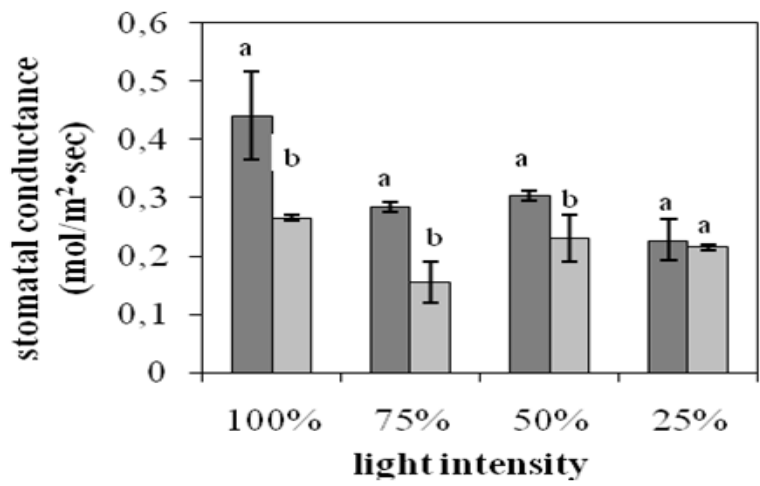

$$
\begin{aligned}
& \square 60 \text { days after the } \\
& \text { installation } \\
& \square 75 \text { days after the } \\
& \text { installation }
\end{aligned}
$$

Figure 5 - The effect of light intensity on the stomatal conductance. Each value of mean and standard error represents measurements from three plants. Significant differences between the means for 60 and 75 days at each light intensity are indicated by different letters $(\mathrm{p}=0.05)$.

\section{Chlorophylls and carotenoids}

The photosynthetic pigments in the shaded plants tended to be higher when compared with the plants exposed to full sunlight. Specifically, at $25 \%$ of FAL, chlorophylls $\mathrm{a}, \mathrm{b}$ and their sum were doubled, while carotenoids presented a $75 \%$ increment (Fig. 6), in comparison with the plants grown at $100 \%$ of FAL. These results were similar with several studies on other plants (Czeczuga 1987; Adamson et al. 1991; Muraoka et al. 2002; De Carvalho Gonçalves et al. 2005; Yang et al. 2007; Mielke and Schaffer 2010). In contrary, the photosynthetic pigment (especially carotenoids) contents of Tradescantia pallida were increased under full sunlight (Sousa Paiva et al. 2003). 


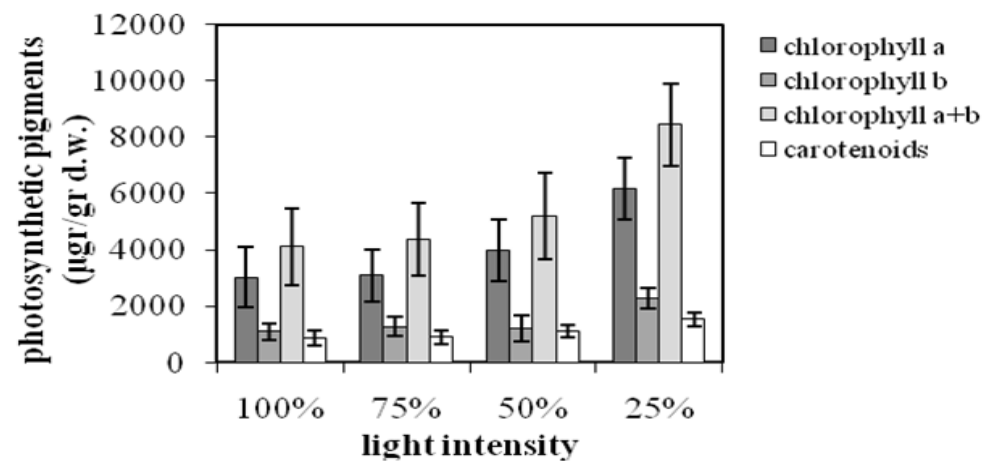

Figure 6 - The effect of light intensity on photosynthetic pigments contents. Each value of mean and standard error represents three replications of measurements.

According to previous studies, shade-plants develop acclimation strategies, including larger and thinner leaves which present even a three-fold increase in chlorophylls (Adamson et al. 1991; Taiz and Zeiger 2002). The synthesis and degradation of the photosynthetic pigments are associated with the plants adaptability to different environments. The chlorophylls are usually synthesized and photo-oxidized in the presence of light. Nonetheless, the excess of light can cause greater degradation and consequently, a reduction in the levels of total chlorophyll (De Carvalho Gonçalves et al. 2005). On the other hand, under deficit light conditions, the plants set a series of compensatory mechanisms into motion such as a substantial increment of the photosynthetic pigments. This response fulfils the function of the photosynthetic antennae absorbing the required light energy (Czeczuga 1987) considering that the highly pigmented leaves show higher light absorption efficiency per unit of leaf biomass, which may allow the plant to achieve a better carbon balance under light limitation (Enriquez and Sand-Jensen 2003). Besides, it has been reported that the efficiency of photosynthesis during sun flecks is higher in the shade tolerant species (Castrillo et al. 2005).

In environments with high solar radiation, the increase of photo-oxidation of chlorophylls depends upon the concentration of carotenoids, which can prevent chlorophylls photo-destruction (Czeczuga 1987; De Carvalho Gonçalves et al. 2005), while in low light environments carotenoids may play a more important role in light absorption and its transfer to chlorophyll (Czeczuga 1987; Taiz and Zeiger 2002).
In conclusion, the observed significant increment of chlorophylls and carotenoids (Fig. 6) at low light conditions, while dry mass productivity (Fig. 1) and photosynthesis (Fig. 3) were high at full sunlight, indicated that $S$. officinalis can properly regulate its metabolism toward the solar radiation conditions and it can be adaptable to different light habitats.

\section{REFERENCES}

Adamson HY, Chow WS, Anderson JM, Vesk M, Sutherland MW. Photosynthetic acclimation of Tradescantia albiflora to growth irradiance: morphological, ultrastructural and growth responses. Physiol. Plant. 1991; 82: 353-359.

An H, Shangguan ZP. Effects of light intensity and nitrogen application on the growth and photosynthetic characteristics of Trifolium repens L. Shengtai Xuebao/ Acta Ecologica Sinica. 2009; 29: 6017-6024.

Assimakopoulos SF, Mavrakis AG, Grintzalis K, Papapostolou I, Zervoudakis G, Konstantinou D, et al. Superoxide radical formation in diverse organs of rats with experimentally induced obstructive jaundice. Redox Rep. 2008; 13: 179-184.

Bettaieb I, Zakhama N, Aidi Wannes W, Kchouk ME, Marzouk B. Water deficit effects on Salvia officinalis fatty acids and essential oils composition. Sci. Hort. 2009; 120: 271-275.

Bozin B, Mimica-Dukic N, Samojlik I, Jovin E. Antimicrobial and antioxidant properties of Rosemary and Sage (Rosmarinus officinalis L. and Salvia officinalis L., Lamiaceae) essential oils. J. Agron. Food Chem. 2007; 55: 7879-7885. 
Castrillo M, Vizcaíno D, Moreno E, Latorraca Z. Specific leaf mass, fresh: dry weight ratio, sugar and protein contents in species of Lamiaceae from different light environments. Rev.Biol. Trop. 2005; 53: 23-28.

Corell M, García MC, Cermeño P. Effect of the deficit watering in the production and quality of the essential oil, in the cultivation of Salvia officinalis L. Acta Hort. 2009; 826: 281-288.

Czeczuga B. Carotenoid contents in leaves grown under various light intensities. Biochem. Sys. Ecol. 1987; 15: 523-527.

De Carvalho Gonçalves JF, De Sousa Barreto DC, Dos Santos Jr. UM, Fernandes AV, Barbosa Sampaio PDT, Buckeridge MS. Growth, photosynthesis and stress indicators in young rosewood plants (Aniba rosaeodora Ducke) under different light intensities. Braz. J. Plant Physiol. 2005; 17: 325-334.

Devecchi M. The use of Labiatae of ornamental interest in the design of parks and gardens. Acta Hort. 2006; 723: 51-57.

Enriquez S, Sand-Jensen K. Variation in light absorption properties of Mentha aquatica L. as a function of leaf form: implications for plant growth. Int. J. Plant Sci. 2003; 164: 125-136.

Ilkiu-Vidal LH, Souza JRP, Viani RAG. Action of potentials of hydrogen on growth and productivity of sage (Salvia officinalis L.). Rev. Bras. Plant. Med. 2010; 12: 43-47.

Lichtenthaler HK. Chlorophylls and carotenoids: pigments of photosynthetic biomembranes. In: Packer L and Douce R, editors. Methods Enzymol. London: Academic Press; 1987. p. 350-382.

Lima CF, Andrade PB, Seabra RM, Fernandes-Ferreira M, Pereira-Wilson C. The drinking of a Salvia officinalis infusion improves liver antioxidant status in mice and rats. J.Ethnopharmacol. 2005; 97: 383389.

Lima CF, Valentao PCR, Andrade PB, Seabra RM, Fernandes-Ferreira M, Pereira-Wilson C. Water and methanolic extracts of Salvia officinalis protect HepG2 cells from t-BHP induced oxidative damage. Chem. Biol. Interact. 2007; 167: 107-115.

Mayer B, Baggio CH, Freitas CS, Dos Santos AC, Twardowschy A, Horst H, et al. Gastroprotective constituents of Salvia officinalis L. Fitoterapia. 2009; 80: 421-426.

Mielke MS, Schaffer B. Photosynthetic and growth responses of Eugenia uniflora L. seedlings to soil flooding and light intensity. Environ. Exper. Bot. 2010; 68: 113-121.
Muraoka H, Tang Y, Koizumi H, Washitani I. Effects of light and soil water availability on leaf photosynthesis and growth of Arisaema heterophyllum, a riparian forest understorey plant. $J$. Plant Res. 2002; 115: 419-427.

Nell M, Vötsch M, Vierheilig H, Steinkellner S, ZitterlEglseer K, Franz C, et al. Effect of phosphorus uptake on growth and secondary metabolites of garden sage (Salvia officinalis L.). J. Sci. Food Agric. 2009; 89: 1090-1096.

Pegoraro RL, de Falkenberg MB, Voltolini CH, Santos M, Paulilo MTS. Production of essential oils in plants of Mentha $x$ piperita L. var. piperita (Lamiaceae) submitted to different light levels and nutrition of the substratum. Rev. Bras. Botan. 2010; 33: 631-637.

Pizzale L, Bortolomeazzi R, Vichi S, Überegger E, Conte LS. Antioxidant activity of sage (Salvia officinalis and S. fruticosa) and oregano (Origanum onites and $O$. indercedens) extracts related to their phenolic compound content. J. Sci Food Agric. 2002; 82: $1645-1651$.

Santos-Gomes PC, Seabra RM, Andrade PB, Fernandes-Ferreira M. Phenolic antioxidant compounds produced by in vitro shoots of sage (Salvia officinalis L.). Plant Sci. 2002; 162: 981-987.

Sousa Paiva ÉA, Dos Santos Isaias RM, Aguiar Vale FH, De Senna Queiroz CG. The influence of light intensity on anatomical structure and pigment contents of Tradescantia pallida (Rose) Hunt. cv. purpurea boom (Commelinaceae) leaves. Braz. Arch. Biol. Techn. 2003; 46: 617-624.

Taarit MB, Msaada K, Hosni K, Hammami M, Kchouk ME, Marzouk B. Plant growth, essential oil yield and composition of sage (Salvia officinalis L.) fruits cultivated under salt stress conditions. Ind. Crop. Prod. 2009; 30: 333-337.

Taiz L, Zeiger E. Plant Physiology. 3rd ed. Sunderland: Sinauer Associates, Inc; 2002.

Wang Y, Guo Q, Jin M. Effects of light intensity on growth and photosynthetic characteristics of Chrysanthemum morifolium. Zhongguo Zhongyao Zazhi. 2009; 34: 1633-1635.

Yang XY, Ye XF, Liu GS, Wei HQ, Wang Y. Effects of light intensity on morphological and physiological characteristics of tobacco seedlings. Chin. J. Appl. Ecol. 2007; 18: 2642-2645.

Zhang S, Ma K, Chen L. Response of photosynthetic plasticity of Paeonia suffruticosa to changed light environments. Environ. Exper. Bot. 2003; 49: 121-133. 